\title{
27. FERROMAGNETIC FRACTION OF CRETACEOUS AND CENOZOIC SEDIMENTS OF THE RIO GRANDE RISE AND BRAZIL BASIN ${ }^{1}$
}

\author{
G. N. Petrova and T. B. Nechaeva, Institute of Physics of the Earth Academy of Sciences of the U.S.S.R., \\ B. Gruzinskaya 10, Moscow 123810, U.S.S.R. \\ G. Z. Gurary, Geological Institute, Academy of Sciences of the U.S.S.R., Pyjevsky 7, Moscow 109017, U.S.S.R. \\ and \\ V. A. Chmerev, Institute of Physics of the Earth Academy of Sciences of the U.S.S.R., B. Gruzinskaya 10, \\ Moscow 123810, U.S.S.R.
}

\begin{abstract}
Investigation of the ferromagnetic fraction of sediments from the Brazil Basin and Rio Grande Rise shows that its main constituents are magnetite and hematite. The magnetite is detrital, but the hematite is both detrital and chemical in origin. Magnetite is the main carrier of the natural remanent magnetization (NRM); therefore, the NRM is detrital remanent magnetization (DRM). In a number of cases, the change of magnetic parameters along the stratigraphic column permits some refinement of the previously defined boundaries of the lithologic units.
\end{abstract}

\section{INTRODUCTION}

At present, paleomagnetic investigations are particularly important in stratigraphic studies, both for intraregional and interregional correlations. Depending on its origin, natural remanent magnetization (NRM) can be synchronous with the process of rock formation; detrital remanent magnetization (DRM) and primary chemical remanent magnetization (CRM) changes can arise at any time after the formation process is over (for example: secondary CRM or viscous remanent magnetization). Secondary magnetization can modify and sometimes fully change primary paleomagnetic characteristics; these changes may lead investigators to erroneous conclusions.

The present report describes the composition and origin of ferromagnetic minerals, those carrying NRM, from the Eocene to Quaternary sediments from Hole 515B (Brazil Basin) and Cretaceous to Miocene sediments from Hole 516F (Rio Grande Rise), both drilled during Deep Sea Drilling Project Leg 72. We focus primarily on the change in composition and quantity of the ferromagnetic minerals in our samples.

\section{METHODS}

This investigation is based on a completely new suite of samples, not treated in laboratories before. The following magnetic methods were used:

1) Differential thermomagnetic analysis (DTMA): the rate of change of saturation magnetization (Js) with respect to temperature$\Delta \mathrm{Js} / \Delta \mathrm{t}^{\circ}\left(\mathrm{t}^{\circ}\right)$-at the first and the second heatings up to $700^{\circ} \mathrm{C}$ (Burov and Yasonov, 1979);

2) Usual thermomagnetic analysis: the dependence of the change in saturation magnetization (Js) on temperature- $\mathrm{Js}\left(\mathrm{t}^{\circ}\right)$-at the first and second heatings up to $700^{\circ} \mathrm{C}$;

3) The method of saturation parameters: the change of saturation remanent magnetization (Jrs) and remanent coercive force $(\mathrm{Hcr})$ after

\footnotetext{
${ }^{1}$ Barker, P. F., Carlson, R. L., Johnson, D. A., et al., Init. Repts. DSDP, 72: Washington (U.S. Govt. Printing Office)
}

heating, cooling, and a new magnetization; at each new heating, the temperature was increased by $100^{\circ} \mathrm{C}$ (Petrova, 1977);

4) The determination of dependence of remanent magnetization (Jr) on magnetic field $\mathrm{H}$ and $\mathrm{Hcr}$;

5) The determination of coercive spectra (CS) of Ir.

Investigations relating to the last two points were mainly carried out with samples that were first heated to $t=280^{\circ} \mathrm{C}$ during thermal cleaning for paleomagnetic studies. A lack of available samples necessitated this reuse; however, our results bear out the validity of using such samples.

DTMA, dependence of Jr(h), and Hcr were carried out on $37 \mathrm{sam}$ ples from Hole 515B and 51 samples from Hole 516F; Js $\left(t^{\circ}\right)$ curves, saturation parameters, and CS were defined for a few samples (eight samples from Hole 515B and 15 from Hole 516F) in order to fully characterize groups of samples with typical DTMA curves.

\section{RESULTS}

All initial curves $\Delta \mathrm{Js} / \Delta \mathrm{t}^{\circ}\left(\mathrm{t}^{\circ}\right)$ and $\mathrm{Js}\left(\mathrm{t}^{\circ}\right)$ have characteristics typical for paramagnetic minerals. The presence of ferromagnetic minerals in the above samples is absolutely clear, because the samples possess NRM intensities of $10^{-6} \pm 10^{-7} \mathrm{emu}$, as well as saturation isothermal remanent magnetization (sIRM) of $10^{-4} \mathrm{emu}$, in spite of the dominance of paramagnetic minerals in the curves. Saturation IRM of paramagnetic minerals is more intense than that of ferromagnetic ones, and Curie points of the ferromagnetic minerals are barely detected because of change of paramagnetic $\operatorname{Ts}\left(\mathrm{t}^{\circ}\right)$ in the temperature interval, where Tc can be expected. According to DTMA curves, the studied samples can be divided into four groups:

1) Samples that show intense formation of new ferromagnetic minerals during heating (Fig. 1A) (these samples mainly occur in the upper parts of the sedimentary column, although hints of this process are noticed in samples from greater sub-bottom depths as well);

2) Samples in which new ferromagnetite mineral does not form during fast heating (about $50 \%$ minute) (Fig. 2A);

3) Samples that contain maghemite; 

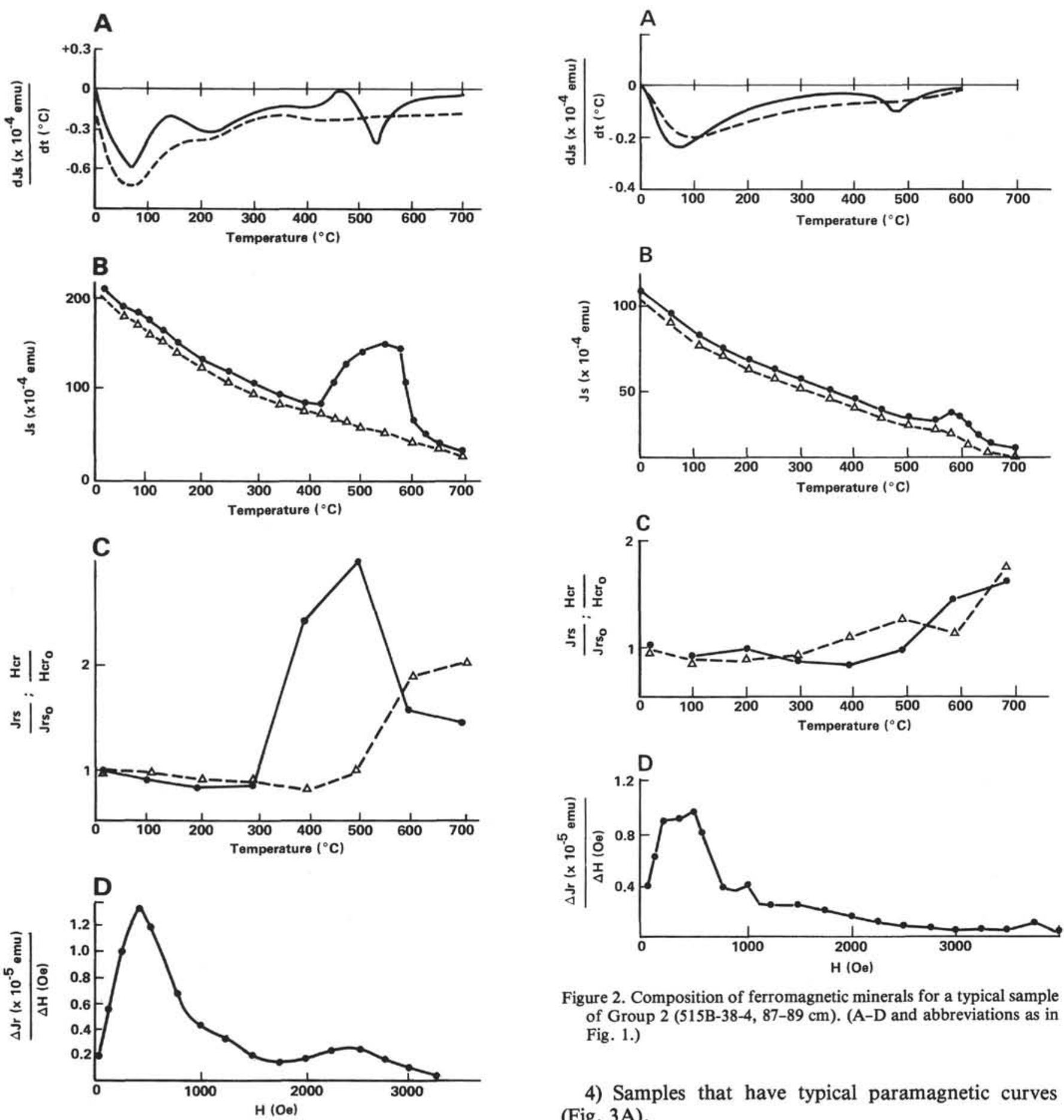

Figure 1. Composition of ferromagnetic minerals for typical sample of Group 1 (515B-46-1, 41-43 cm). A. Differential thermomagnetic analysis; solid line indicates data taken after the first heating; dashed line indicates data taken after the second heating. B. Change of saturation remanent magnetization (Jrs); solid dots: first heating; triangles: second heating. C. Change of saturation parameters Jrs and $\mathrm{Hcr}$ (remanent coercive force) after progressive heatings. (Measurements of Jrs and Hcr are made after heating to definite temperature and cooling to room temperature.) Solid circles $=\mathrm{Jrs}$; triangles $=\mathrm{Hcr}$. D. Coercive spectrum (unheated sample). $\mathrm{dJ} s=$ rate of change of saturation magnetization; $\mathrm{t}=$ temperature; subscript $\mathrm{o}=$ original; $\mathrm{Jr}=$ remanent magnetization; $\mathrm{H}=$ field strength.

Figure 2. Composition of ferromagnetic minerals for a typical sample of Group 2 (515B-38-4, 87-89 cm). (A-D and abbreviations as in Fig. 1.)

4) Samples that have typical paramagnetic curves (Fig. 3A).

The distributions of the different kinds of samples in the holes are represented in Figure 4C.

In our study, the diagnosis of ferromagnetic minerals is complicated. A typical DTMA curve for the first groups of samples is given in Figure 1A. Minima between 80 and $240^{\circ} \mathrm{C}$ are caused by dehydration (Burov and Yasonov, 1979). Most curves show this effect, even though intensity changes from one sample to another and the effect has the tendency to decrease with the increasing sub-bottom depth. After $300^{\circ} \mathrm{C}, \Delta \mathrm{Js} / \Delta \mathrm{T}^{\circ}$ begins to increase, reflecting the intensive formation of 

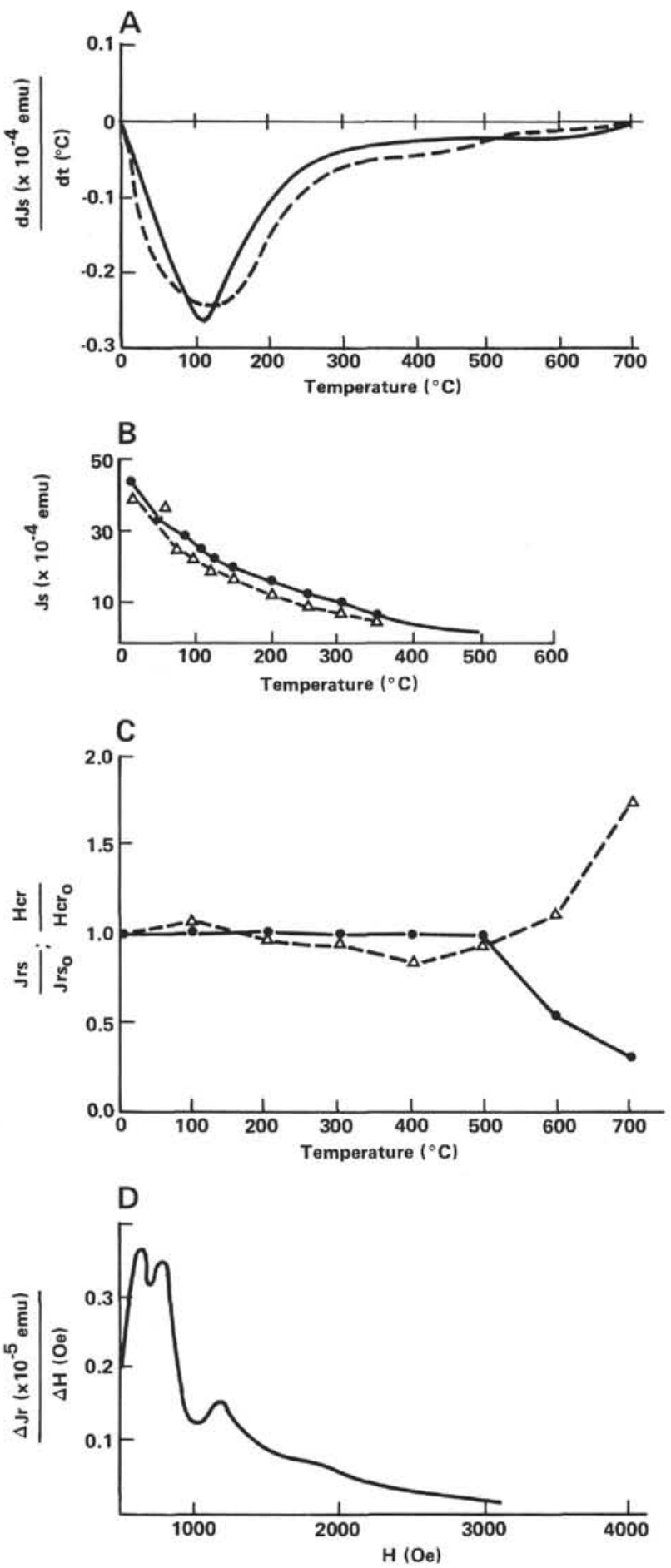

Figure 3. Composition of ferromagnetic minerals for a typical sample of Group 3 (516F-82-2, 92-94 cm). (A-D and abbreviations as in Fig. 1.)

a new ferromagnetic mineral (Fig. 1A). The maximum of this process is reached at a temperature of 500 $\pm 20^{\circ} \mathrm{C}$; then the curve declines sharply, indicating destruction of the ferromagnetic grains, approach of the Curie point ( $\mathrm{Tc}$ ), or both. A minimum is reached at 560 $\pm 20^{\circ} \mathrm{C}$; then the curve approaches the zero line. For the samples of the second group, $\mathrm{Js}\left(\mathrm{t}^{\circ}\right)$ of ferromagne- tite is not decreased by the formation and destruction of new ferromagnetic minerals (Fig. 2). The DTMA method estimation of Tc, taking the maximum of the second derivative,$^{2}$ is near to the Tc of magnetite. The same occurs with the samples of the third group (Fig. 3).

For convenience of interpretation of the $\Delta \mathrm{Js} / \Delta \mathrm{t}^{\circ}$ results, histograms of distribution of temperature intervals were drawn, in which Tc of the ferromagnetic minerals in samples from the first three groups are present (Fig. 4). The extreme right column of each histogram indicates the number of cases in which Tc could not be determined because of a considerable predominance of paramagnetic components (samples of Group 4). Sharp maxima of the histograms for both holes correspond to the temperatures of the Tc (about $580^{\circ} \mathrm{C}$ ) of magnetite (Figs. 4A-B). Magnetite is present in samples of all the three groups (Figs. 1-3). Although hematite occurs in a number of samples, magnetite is likely to be the main ferromagnetic mineral; two-thirds of the samples from Hole 515B and three-fourths of the samples from Hole 516F register no hematite (Fig. 5).

The paramagnetic character of the $\mathrm{Js}\left(\mathrm{t}^{\circ}\right)$ and $\Delta \mathrm{Js} /$ $\Delta t\left(t^{\circ}\right)$ curves for samples from the lower part of Hole 516F (Group 4, samples from the Cretaceous) prevents discovery of the initial ferromagnetic Tc, and suppositions regarding the composition of the ferromagnetic fraction are made only on the basis of changes of saturation magnetization. At temperatures above $500^{\circ} \mathrm{C}$ in these samples, Hcr falls from more than 2000 Oe to between 300 and 500 Oe; Jrs increases by a factor of 2 to 3; and Js increases by 10 to $40 \%$ (Fig. 3C). Such trends of saturation parameters at initial $\mathrm{Hcr}$ greater than $2 \mathrm{kOe}$ are possible for hydroxides, although destruction of hydroxides usually occurs at lower temperatures. Because this part of Hole $516 \mathrm{~F}$ lacks an age analogy in Hole 515B, it will not be discussed further.

Thus, magnetite and hematite are the main ferromagnetic minerals throughout most of Holes 515B and 516F; samples of lower parts of Hole 515B also have maghemite, and Cretaceous samples from Hole 516F have hydroxides.

Before considering possible origins of these ferromagnetic minerals, we should determine if some of these are formed by laboratory heating. Because the product is very unstable, it is unlikely that it is either magnetite or hematite. Repeated heating produced a trend for $\mathrm{Js}\left(\mathrm{t}^{\circ}\right)$ that indicates no traces of new minerals (Figs. 1A and $1 \mathrm{C}$ ). The curves of saturation parameters (Fig. 1C) show that its formation begins after $300^{\circ} \mathrm{C}$ and that it is destroyed completely by $500^{\circ} \mathrm{C}$. The appearance of this ferromagnetic mineral at a temperature of $400^{\circ} \mathrm{C}$ makes Jrs increase 2-20 times. After it is destroyed, Jrs returns to almost its initial value. At first $\mathrm{Hcr}$ decreases by

\footnotetext{
2 In the DTMA method, $\mathrm{Tc}$ is estimated by the maximum of the second derivative of $\mathrm{Js}$ $\left(t^{\circ}\right)$. In figures of this paper, the first derivative of $J s\left(t^{\circ}\right)$ is given, i.e., Tc can be estimated by the most pronounced rate of increase of $\mathrm{dJs} / \mathrm{dt}$. For the first group of samples (Fig. 1A), it is difficult to be sure of the correct estimate of $\mathrm{Tc}$ because of the formation of new ferromagnetic minerals in temperature interval of $400-500^{\circ} \mathrm{C}$. The increase of $\mathrm{dJs} / \mathrm{dt}$ in the interval of $550-600^{\circ} \mathrm{C}$ is a result of this process. The samples of the third group (Fig. 3A) have the curves typical for paramagnetic minerals, but samples of the second group are somewhat disturbed by a new ferromagnetic mineral, producing a $\mathrm{Tc}$ in the interval between 550 and $650^{\circ} \mathrm{C}$. The same picture can be seen in the curves for $\mathrm{Js}\left(\mathrm{t}^{\circ}\right)$ (Figs. 1B, 2B, 3B).
} 

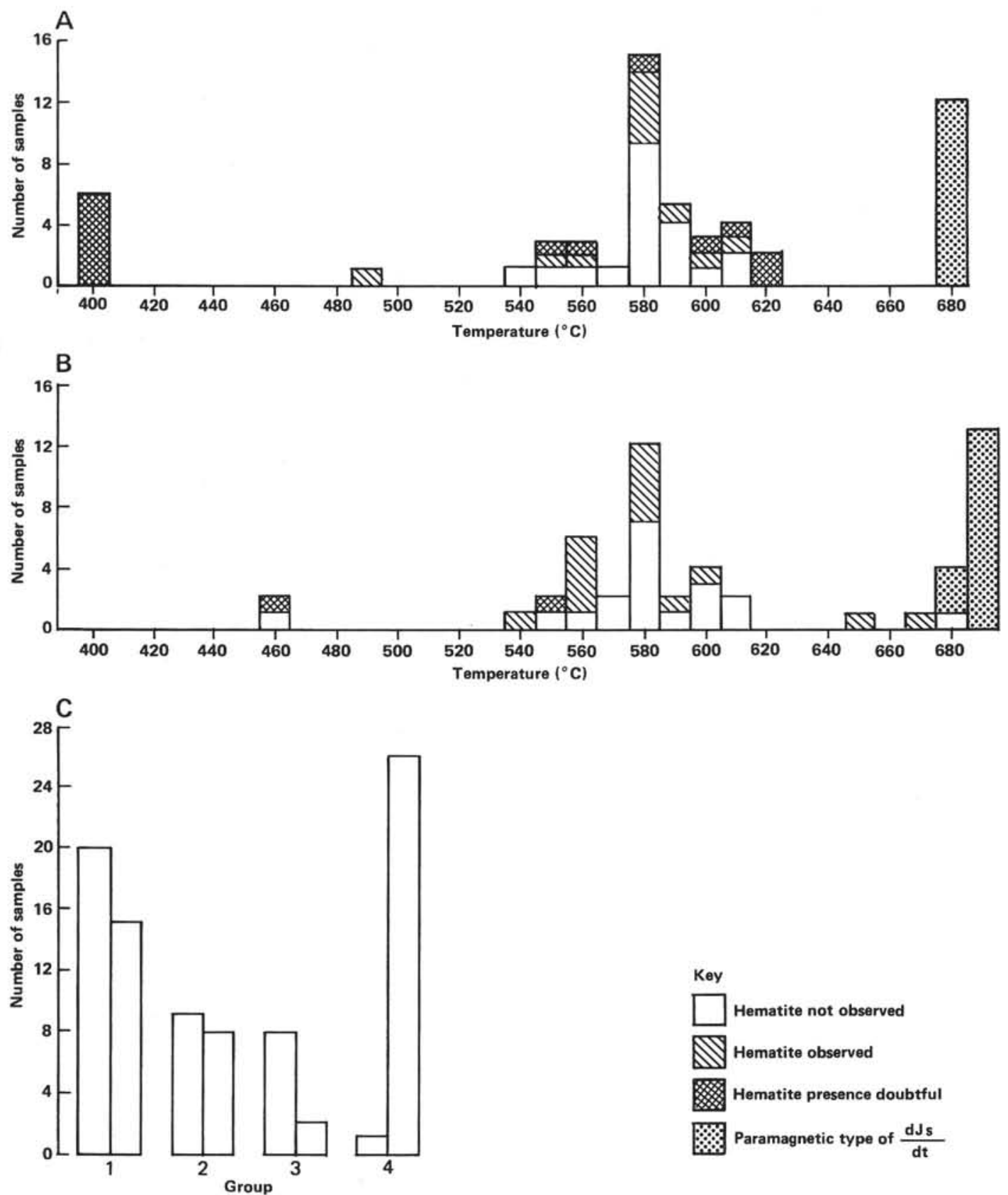

Figure 4. Distribution of Curie point (Tc) estimated by differential thermomagnetic analysis. A: Hole 515B, B: Hole $516 \mathrm{~F}, \mathrm{C}$ : distribution in Hole 515B (the left bar of each pair) and 516F (the right bar of each pair) of samples of different types: (1) samples in which laboratory heating formed a new ferromagnetic mineral (see Fig. 1), (2) samples in which ferromagnetic minerals did not form (see Fig. 2), (3) samples in which maghemite was present, and (4) samples in which the paramagnetic parts of thermocurves did not allow determination of Tc (see Fig. 3).

$30-50 \%$, characteristic of the early stage of formation of new ferromagnetic grains (particularly their supermagnetic part). Then Hcr increases; the rate for soft samples is twice as great as that for hard samples. A distinct trace of hematite appears in some DTMA curves (Fig. 5F). Similar changes of magnetic properties in the same temperature interval were observed when siderite, lepidocrocite, and other minerals are destroyed (Rybak, 1971; Bagin et al., 1974). Laboratory heating, therefore, does not lead to the appearance of magnetite as a new ferromagnetic mineral but can lead to the formation of hematite. Perhaps hematite, or some portion of it, was formed in the sediments as a result of in situ heating.

We can assume the following origin of the most important potential carriers of NRM:

1) Magnetite is the primary ferromagnetic mineral in these sediments. Its origin can be either detrital, introduced by the breakdown of magnetite-bearing parent 

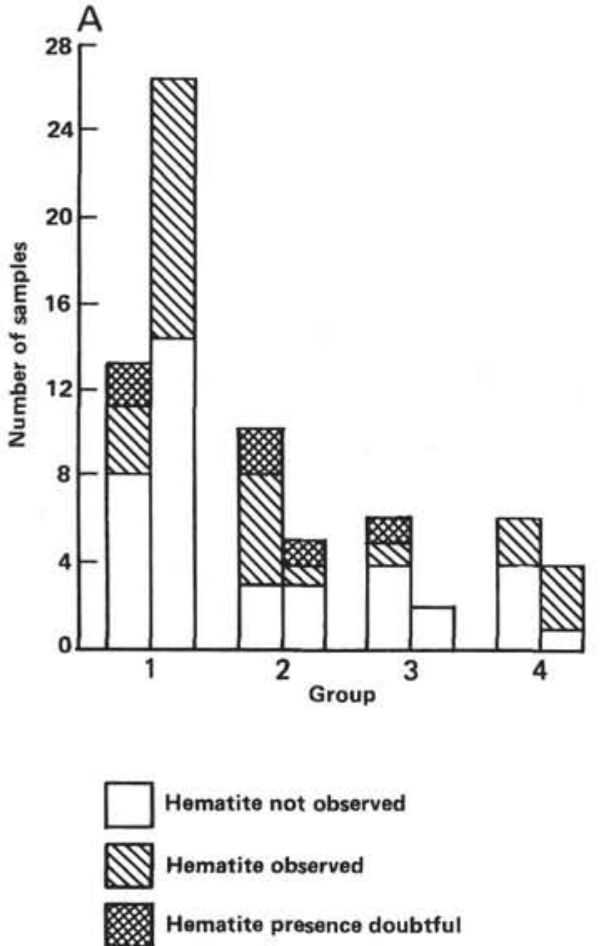
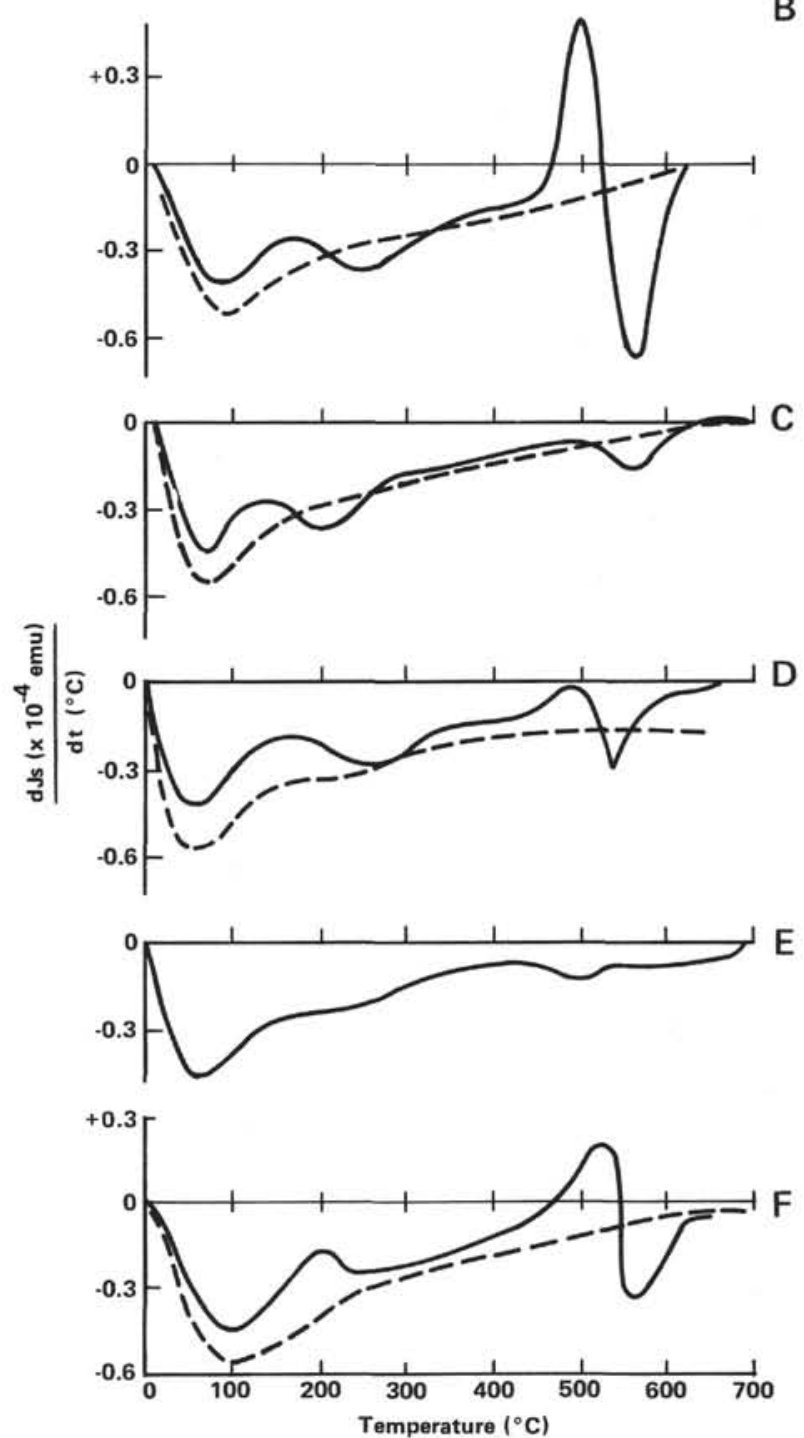

Figure 5. A. The presence of hematite in samples from Hole 515B (the left bar of each pair) and Hole 516F (the right bar of each pair). B. Group 1, no hematite (Sample 515B-50-1, 55-57 cm). C. Group 2, apparently no hematite, but irregularities of the curve do not allow us to be sure (Sample 515B-46-5, 89-91 cm). D. Group 3, the curve dJs/dt ${ }^{\circ}$ approaches asymptotically to the abscissa in the temperature region of $620-660^{\circ} \mathrm{C}$ (Sample $516 \mathrm{~F}-29-1,56-58 \mathrm{~cm}$ ). E. Group 4, hematite is present (Sample $516 \mathrm{~F}-51-4,104-106 \mathrm{~cm}$ ). F. Hematite appears after destruction of new ferromagnetic (Sample 516F-23-2, 65-67 cm).

Thermomagnetic Curves B-E correspond to Columns 1-4 of the histograms. Dashed curves represent second heating; solid curves represent first heating.

rocks of neighboring terrains, by volcanic fallout, or by chemical processes introduced at early stages of the formation of the rocks.

2) Hematite results from the natural process of paramagnetic mineral transformation, a process that also occurs during the course of laboratory heating. It can also be a product of magnetite oxidation and even have a partially detrital origin.

3) The maghemite in the lower part of Hole 515B is associated with oxidation of primary magnetite, supporting the interpretation that the hematite is secondary.

4) The hydroxides present in great amounts in the lower part of $516 \mathrm{~F}$ are most likely of secondary origin.

\section{C}




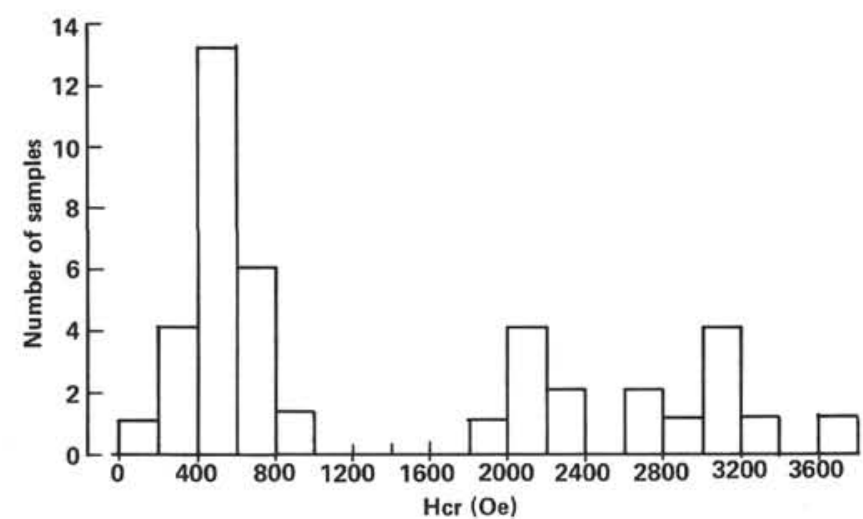

Figure 6. Distribution of remanent coercive force $(\mathrm{Hcr})$ in the samples from Hole $516 \mathrm{~F}$.

Table 1. Magnetization data for Hole 516F.

\begin{tabular}{|c|c|c|c|}
\hline $\begin{array}{l}\text { Core-section } \\
\text { (interval in } \mathrm{cm} \text { ) }\end{array}$ & $\begin{array}{l}\mathrm{Hc} \\
(\mathrm{Oe})\end{array}$ & $\left(\times 10^{-6} \mathrm{Jr}\right.$ & $\begin{array}{c}\text { Jrs } \\
\left(\times 10^{-6} \mathrm{emu}\right)\end{array}$ \\
\hline $19-2,103-105$ & 600 & 0.1 & 100 \\
\hline $22-1,48-50$ & 700 & 0.1 & 220 \\
\hline $25-2,34-36$ & 500 & 0.1 & 180 \\
\hline $26-1,86-88$ & 350 & 0.4 & 700 \\
\hline $27-3,8-10$ & 400 & 0.1 & 250 \\
\hline $29-1,56-58$ & 400 & 0.1 & 200 \\
\hline $30-6,5-7$ & 450 & 0.03 & 200 \\
\hline $32-4,41-43$ & 500 & 0.1 & 70 \\
\hline $52-3,24-26$ & 800 & 0.4 & 250 \\
\hline $60-1,44-46$ & 400 & 0.1 & 100 \\
\hline $67-1,142-144$ & 500 & 0.05 & 900 \\
\hline $67-3,7-9$ & 500 & 0.1 & 500 \\
\hline $71-1,143-145$ & 700 & 0.05 & 500 \\
\hline $72-3,131-133$ & 900 & 0.1 & 400 \\
\hline $74-3,89-91$ & 700 & 0.2 & 1150 \\
\hline $77-1,69-71$ & 700 & 0.5 & 2100 \\
\hline $81-2,14-16$ & 300 & 0.1 & 20 \\
\hline $84-3,40-42$ & 450 & 0.01 & 35 \\
\hline $87-1,61-63$ & 600 & 0.05 & 50 \\
\hline $88-1,131-137$ & 1800 & 0.8 & 400 \\
\hline $90-4,40-42$ & 2100 & 0.7 & 250 \\
\hline $91-3,45-47$ & 2200 & 0.9 & 500 \\
\hline $92-3,33-35$ & 2150 & 0.9 & 400 \\
\hline $93-1,35-37$ & 2100 & 0.4 & 300 \\
\hline $94-1,57-59$ & 2100 & 0.9 & 400 \\
\hline $95-1,69-71$ & 2200 & 0.35 & 1100 \\
\hline $98-5,74-76$ & 500 & 0.02 & 50 \\
\hline $104-1,13-15$ & 500 & 0.02 & 130 \\
\hline $104-1,50-52$ & 3100 & 0.4 & 60 \\
\hline $104-1,78-80$ & 3000 & 0.9 & 500 \\
\hline $104-1,91-93$ & 3100 & 0.4 & 500 \\
\hline $104-1,112-114$ & 3100 & 0.25 & 350 \\
\hline $105-3,22-24$ & 2800 & 1.15 & 1700 \\
\hline $106-1,63-65$ & 2600 & 0.9 & 1400 \\
\hline $108-1,144-146$ & 2700 & 1.56 & 1000 \\
\hline $110-4,83-85$ & 700 & 0.25 & 140 \\
\hline $112-2,76-78$ & 400 & 0.1 & 40 \\
\hline $113-2,32-34$ & 200 & 0.1 & 200 \\
\hline $114-2,71-73$ & 3300 & 0.25 & 150 \\
\hline $118-1,34-36$ & 3600 & 0.4 & 700 \\
\hline $125-1,120-122$ & 300 & 0.2 & 20 \\
\hline $127-4,138-140$ & 100 & 115 & $177,000^{*}$ \\
\hline
\end{tabular}

Note: $\mathrm{HC}=$ coercive field; $\mathrm{Jr}=$ natural remanent magnetization intensity; Jrs = saturation remanent intensity. * = rust flake from drill pipe scale.
3D). CS of all samples studied have sharp maxima in the field between 200 and 500 Oe, typical for multidomain magnetites with grains of different sizes.

Sample 515B-46-1, 41-43 cm (Group 1) has a maximum coercive spectrum (CS) in the field of about $400 \mathrm{Oe}$ ( $\mathrm{Hcr}$ of this sample before heating was $545 \mathrm{Oe}$ ); the right branch of CS curve is less sharp than the left one and is skewed to fields of $1200-1500 \mathrm{Oe}$, indicating weak oxidation. Sample 515B-46-5, 89-91 cm (Group 2), besides having a sharp maximum in the field of $200 \mathrm{Oe}$, also has a weakly expressed maximum in the field of about $1600 \mathrm{Oe}$ (Fig. 2D). The second maximum may belong to hematite, traces of which are recorded on thermomagnetic curves. In this case, hematite may have an origin independent of magnetite. An almost symmetric CS curve and the presence of a separate maximum near 1600 Oe argues in favor of this supposition. Formation and destruction of new ferromagnetic grains probably occurs in nature, and some of the resulting grains are probably hematite, but we cannot exclude the possibility that the hematite or a part of it may be primary.

Sample 515B-38-4, 87-89 cm was almost unchanged by laboratory heating (Fig. 2). The thermomagnetic analysis (TMA) curves show the presence of hematite. The wide maximum and skewed slope of the right branch of the CS curve points to magnetite grains of different sizes and intensive development of processes that oxidize magnetite to hematite.

The Tc of Sample $516 \mathrm{~F}-33-3,92-94 \mathrm{~cm}$ is offset to $600^{\circ} \mathrm{C}$; its $\mathrm{Hcr}=600 \mathrm{Oe}$. The paramagnetic form of the TMA curves of Samples 516F-63-4, 102-104 cm; 516F$65-1,15-17 \mathrm{~cm}$; and $516 \mathrm{~F}-86-2,92-94 \mathrm{~cm}(\mathrm{Hcr}=880$, 950 , and $1200 \mathrm{Oe}$, respectively) hardly reveals a Tc near to that of magnetite $\left(580^{\circ} \mathrm{C}\right)$. The TMA curve of Sample $516 \mathrm{~F}-109-1,80-82 \mathrm{~cm}$ is paramagnetic, and its saturation parameters show the presence of hydroxides.

These samples have sharp maxima of their CS curves in the region characteristic of magnetite and right branches skewed to $1.5 \mathrm{kOe}$ (Sample 516F-33-3, 92$94 \mathrm{~cm}$ ), to $3 \mathrm{kOe}$ (Sample 516F-65-1, 15-17 cm), and to 4 kOe (Sample 516F-86-2, 92-94 cm), probably a result of increasing of oxidation processes with increasing depth.

The CS of Sample 516F-63-4, 102-104 cm, the ferromagnetic fraction of which was unchanged by laboratory heating, is more complicated. The absence of distinct signs of hematite does not allow us to relate the maximum near 800 Oe to hematite. Perhaps it is very fine-grained magnetite or second-generation magnetite? Oxidation of magnetite to hematite is reflected in the skewed right branch of CS curve, which reaches $3 \mathrm{kOe}$.

As the CS of Sample 516F-109-1, 80-82 cm shows, for sediments with paramagnetic TMA curves, each also has a distinct maximum in its CS. That maximum could belong to magnetite. The presence of hydroxides is reflected in right branch of $\mathrm{CS}$, which stretches to more than $7 \mathrm{kOe}$.

The analysis of CS curves shows a subordinate position of hematite compared to magnetite and the obvious presence of magnetite in the deeper sediments of this 
region. Thus, analysis of the CS curves confirms that the chief ferromagnetic mineral in the studied rocks is magnetite, with some hematite present in a number of samples.

In order to identify which mineral is the NRM carrier, the NRM intensity was measured at the Morin transition and at the isotropic point of magnetite. For this purpose, the samples were first cooled to melting temperature for solid $\mathrm{CO}_{2}\left(-80^{\circ} \mathrm{C}\right)$ and then to the temperature of liquid nitrogen $\left(-196^{\circ} \mathrm{C}\right)$. Jrs was measured by the same procedure, for control.

The good agreement between the results of thermomagnetic analysis and that of Jrs cooling (Table 2) allows us to accept with confidence the results of the samples' cooling. NRM of Samples 515B-40-4, 93-95 cm; $516 \mathrm{~F}-101-1,119-121 \mathrm{~cm}$; 515B-44-3, 93-95 cm; and $516 \mathrm{~F}-31-5,20-22 \mathrm{~cm}$ can be attributed to magnetite (Table 2). As for Sample 515B-48-4, 134-136 cm, hematite probably plays a significant role in NRM, but no role was discovered for it in the Jrs curves. In other words, the main ferromagnetic mineral, magnetite, is also the main NRM carrier, although in a number of cases hematite can be a carrier of a rather significant part of NRM.

As shown above, the minerals, particularly magnetite, in our samples are probably primary and of detrital or chemical origin.

The detrital nature of the NRM (and consequently of magnetite) can be supposed according to the following considerations. (1) Jri (anhysteretic remanent magnetization) was created in a field nearly equal to the Earth's $(0.3 \mathrm{Oe})$ but has 10 times as much value as $\mathrm{Jr}(=\mathrm{NRM})$ of corresponding samples. (2) For multidomain grains (magnetite in studied samples most probably is multidomain), the CRM increases with increasing Hcr (with decreasing grain size). CRM properties are still poorly known, but general points of view of CRM origin and a number of experiments argue in favor of such a regularity (Vigilanskaya and Tretjak, 1974). For a wide range

Table 2. Magnetization ( $\mathrm{Jrs}$ and $\mathrm{Jr}$ ) changes after cooling in order to control the presence of magnetic and hematite.

\begin{tabular}{|c|c|c|c|c|c|c|c|}
\hline \multirow[b]{2}{*}{ Hole } & \multirow{2}{*}{$\begin{array}{l}\text { Core-section } \\
\text { (interval in } \mathrm{cm} \text { ) }\end{array}$} & \multicolumn{3}{|c|}{$\mathrm{Jr} \times 10^{-5} \mathrm{emu}^{\mathrm{a}}$} & \multicolumn{3}{|c|}{$\mathrm{Jrs} \times 10^{-5} \mathrm{emu}^{\mathrm{b}}$} \\
\hline & & $\mathrm{T}$ & $\mathrm{Cl}$ & $\mathrm{C} 2$ & $\mathrm{~T}$ & $\mathrm{Cl}$ & $\mathrm{C} 2$ \\
\hline \multirow[t]{8}{*}{ 515B } & $36-1,48-50$ & & & & 108.5 & 107.5 & 100.0 \\
\hline & $40-2,41-42$ & & & & 119.0 & 116.5 & 111.0 \\
\hline & $40-4,93-95$ & 2.62 & 2.60 & 2.18 & & & \\
\hline & $44-3,93-95$ & 1.90 & 1.78 & 1.61 & & & \\
\hline & $45-2,49-51$ & & & & 64.5 & 64.5 & 60.0 \\
\hline & $48-4,134-136$ & 1.11 & 1.00 & 0.93 & & & \\
\hline & $49-1,140-142$ & & & & 56.0 & 56.0 & 52.0 \\
\hline & $55-1,3-5$ & & & & 64.0 & 63.5 & 59.5 \\
\hline \multirow[t]{8}{*}{$516 \mathrm{~F}$} & $19-2,103-105$ & & & & 25.0 & 24.5 & 23.5 \\
\hline & $31-5,20-22$ & 0.43 & 0.39 & 0.27 & & & \\
\hline & $32-4,41-43$ & & & & 17.0 & 16.5 & 15.5 \\
\hline & $52-3,24-26$ & & & & 71.0 & 66.5 & 64.5 \\
\hline & $87-1,61-63$ & & & & 11.0 & 10.5 & 10.0 \\
\hline & $101-1,119-121$ & 0.28 & 0.27 & 0.18 & & & \\
\hline & $104-1,78-80$ & & & & 74.0 & 70.5 & 68.0 \\
\hline & $127-4,138-140$ & & & & 133.0 & 125.5 & 112.5 \\
\hline
\end{tabular}

Note: $\mathrm{T}=$ temperature is $20^{\circ} \mathrm{C} ; \mathrm{Cl}=$ after cooling to $-80^{\circ} \mathrm{C} ; \mathrm{C} 2=$ after cooling to $-196^{\circ} \mathrm{C}$; a blank indicates that no value was available.

a After heating to $230^{\circ} \mathrm{C}$.

$b_{\mathrm{H}}=10^{3} \mathrm{Oe}$. of grain sizes, DRM is not dependent on size. The lack of dependency of Ir/Irs on Hcr is also evident (Fig. 7) and that, in the authors' opinion, favors an detrital origin of NRM for most of the sediments studied.

The main ferromagnetic mineral in the rocks under consideration is magnetite. It is mainly fine grained but multidomain. Hematite is likely to result from magnetite oxidation, or disintegration of paramagnetic minerals, or may be of primary origin. Generally, the oxidation processes are of variable intensity throughout the sediment column, but in Hole $516 \mathrm{~F}$ oxidation increases with age. Abundant hydroxides characterize the Cretaceous sediments of Hole $516 \mathrm{~F}$. Conditions in some layers lead to the formation of unstable ferromagnetic minerals which in turn disintegrate to hematite. Magnetite is the main carrier of NRM, which most probably is DRM, therefore NRM can be used for magnetostratigraphic investigations.

\section{DISCUSSION}

Analyses of Jrs and $\mathrm{Hcr}$, indicators of the change of composition and quantities of ferromagnetic minerals with sub-bottom depth in Hole 516F located on the Rio Grande Rise (Fig. 8), leads to the following conclusions:

1) The concentration of the ferromagnetic fraction in Lithologic Units 7 and 8 is different, but the composition of that fraction is obviously similar; in both units, magnetite is the main component.

2) Relatively high values of $\mathrm{Hcr}$ characterize Lithologic Subunits 5b, 6a, and $6 \mathrm{~b}$. At the same time, magnetic characteristics allow us to make more detailed subdivisions of these units into horizons (Fig. 8). In a number of cases, the boundaries of the horizons based on magnetic data do not coincide with those based on lithology (Barker et al., 1981).

Most of Lithologic Subunit $6 \mathrm{~b}$ can be identified by the low values of Jrs and high values of Hcr (Fig. 8a). Meanwhile, the upper part of Subunit $6 \mathrm{~b}$ and lower part of Subunit $6 \mathrm{a}$ form one horizon with decreased values of both Jrs and Hcr. Subunit 6A can be divided into three horizons: one with increased values of Jrs and $\mathrm{Hcr}$, one with decreased values of Jrs and Hcr, and one

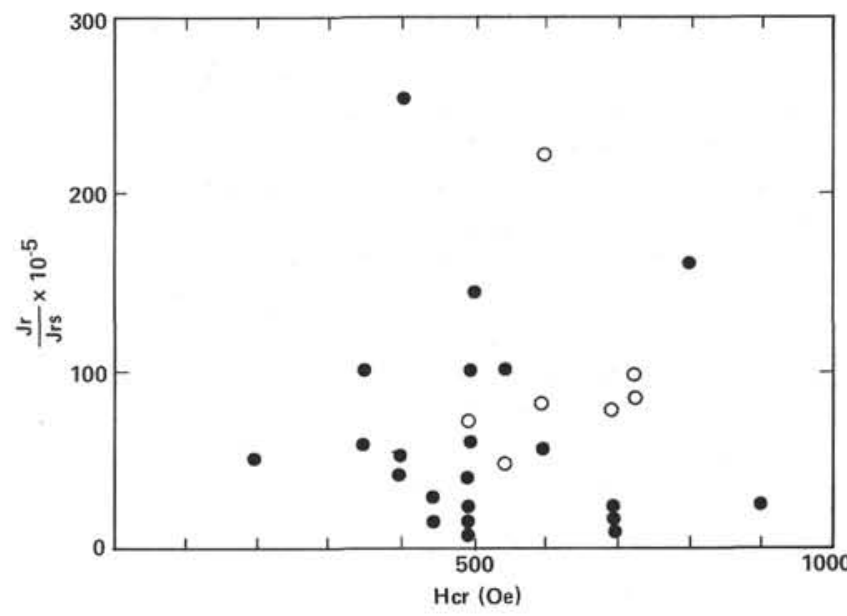

Figure 7. Remanent coercive force (Hcr) versus the value of remanent magnetization $(\mathrm{Jr})$ normalized to saturation remanent magnetization (Jrs). 

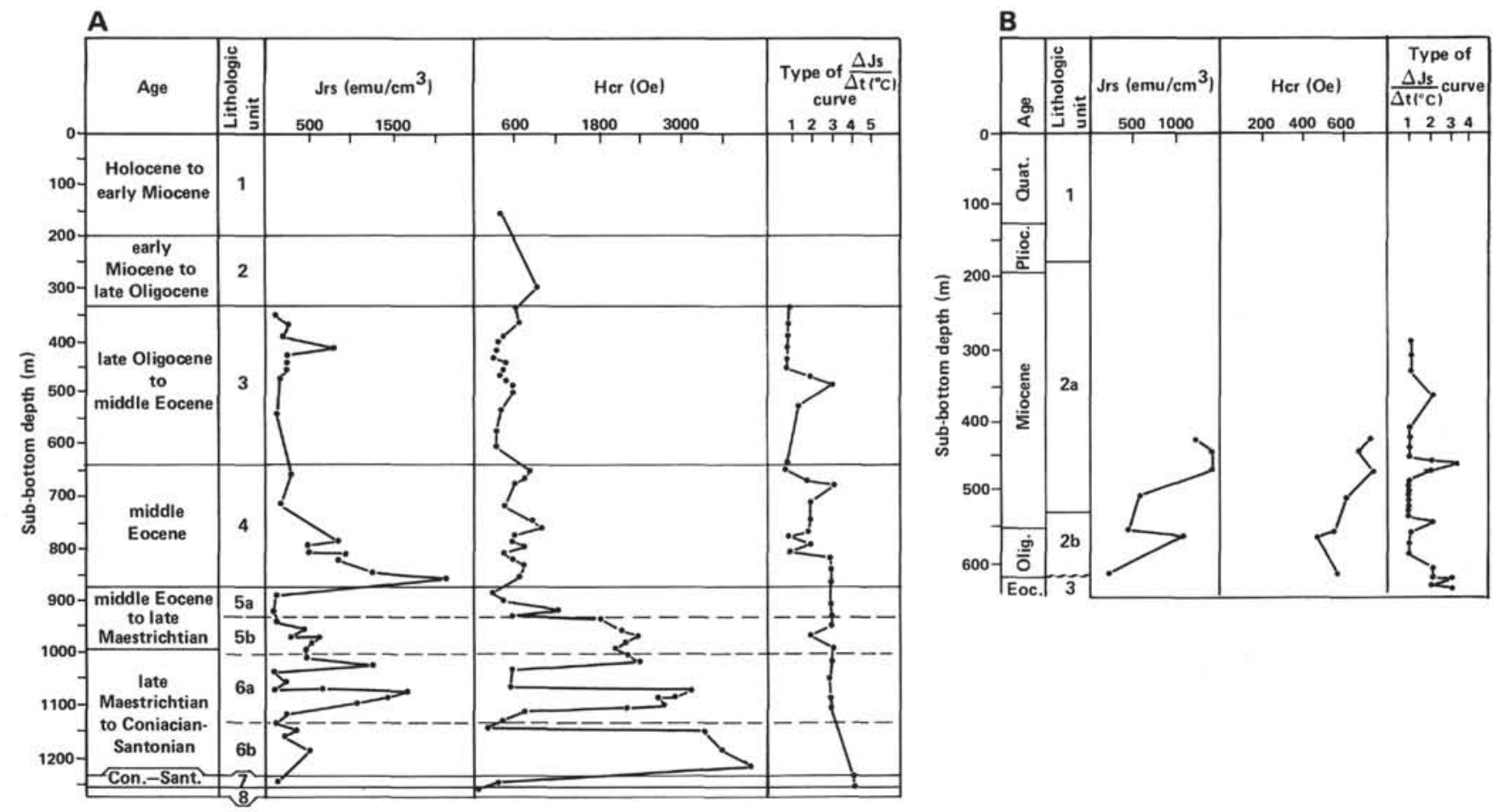

Figure 8. Variation of magnetic characteristics of samples from Holes 515B $(8 \mathrm{~A})$ and $516 \mathrm{~F}(8 \mathrm{~B})$. Jrs $=$ saturation remanent magnetization, $\mathrm{Hcr}=$ remanent coercive force, $\Delta \mathrm{Js}=$ rate of change of saturation magnetization, $\mathrm{t}=$ temperature.

with increased $\mathrm{Hcr}$ and average values of Jrs. The last horizon, beginning in upper part of this unit, continues up to the upper boundary of Subunit 5b. Very low values of Jrs and low values of $\mathrm{Hcr}$ characterize Subunit 5a and distinguish it from the sediments of neighboring lithologic units.

3) Several new horizons, whose differences are not as obvious as previous ones, are distinguished in the remaining lithologic units. The rocks of the lower half of Unit 4 are exceptions in their higher Jrs values. All sediments of Unit 4 (middle Eocene) have somewhat higher values of Hcr compared wtih those of Unit 3 (middle Eocene to upper Oligocene).

Sharp changes of Jrs and Hcr occur in all Hole 516F lithologic units, between Unit 8 and up to the middle of Unit 4. The presence of hydroxides is characteristic for all these rocks, but oxidizing conditions are different for this part of section in comparison with the upper part of the hole. Unit 3 and the upper part of Unit 4 have the same ferromagnetic fraction composition. Types 1 and 2 of $\Delta \mathrm{Js} / \Delta \mathrm{t}$ curves differ from each other only by the intensity of change of laboratory heating. Concentration of the ferromagnetic fraction in Units 3 and 4 of Hole $516 \mathrm{~F}$ varies only slightly; changes of $\mathrm{Hcr}$ are of regular character (Hcr changes twice), and they are evidence of a change in the size of the magnetite grains. The regularity of these alternations allows us to suppose that they were associated with changing exterior conditions.

\section{ACKNOWLEDGMENTS}

The authors are very grateful to N. Hamilton and A. Suzyumov for sharing their samples, to B. Burov and P. Yasonov for assistance in carrying out the experiments, to G. Pospelova and V. Vadkovsky for their peer reviews of the article, as well as to W. Coulbourn for his assistance.

\section{REFERENCES}

Bagin, V. I., Gendler, T. S., Rybak, R. S., and Kizmin, R. N., 1974. Temperature transitions of natural solid solution $(\mathrm{Fe}, \mathrm{Mg}) \mathrm{CO}_{3}$. Izv. Akad. Nauk Arm. SSR, Fiz. Zemli, 6:73-84. (in Russian)

Barker, P. F., Carlson, R. L., Johnson, D. A., and Shipboard Scientific Party, 1981. Deep Sea Drilling Project Leg 72: southwest Atlantic paleocirculation and Rio Grande Rise tectonics. Bull. Geol. Soc. Am., Pt. 1, 92:294-309.

Burov, B. V., and Yasonov, P. G., 1979. Introduction in differential thermomagnetic analysis of rocks. Kazan State University, Kazan City. (in Russian)

Petrova, G. N., 1977. Laboratory methods at paleomagnetic investigations. Geomagnetic Collection of Papers, 19:40-49.

Rybak, R. S., 1971. About diagnostics of maghemite by thermomagnetic method. Izv. Akad. Nauk. Arm. SSR, Fiz. Zemli, 4:98-101. (in Russian)

Vigilianskaya, L. I., and Tretiak, A. N., 1974. Some parameters of chemical remanent magnetization and their changes in heating process. Geophysica Collection of Papers of AN Ukranian SSR, 57:76-82. (in Russian)

Date of Initial Receipt: September 7, 1982 